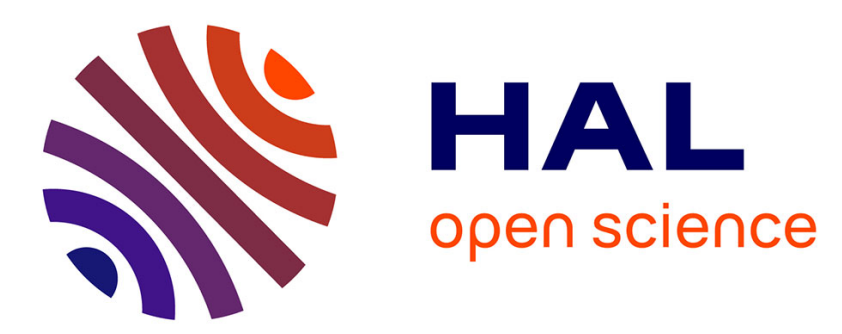

\title{
Effect of the Ligand Binding Strength on the Morphology of Functionalized Gold Nanoparticles
}

Chen-Hui Chan, Floriane Poignant, Michael Beuve, Elise Dumont, David Loffreda

\section{- To cite this version:}

Chen-Hui Chan, Floriane Poignant, Michael Beuve, Elise Dumont, David Loffreda. Effect of the Ligand Binding Strength on the Morphology of Functionalized Gold Nanoparticles. Journal of Physical Chemistry Letters, 2020, pp.2717-2723. 10.1021/acs.jpclett.0c00300 . hal-02519412

\section{HAL Id: hal-02519412 \\ https://hal.science/hal-02519412}

Submitted on 30 Nov 2020

HAL is a multi-disciplinary open access archive for the deposit and dissemination of scientific research documents, whether they are published or not. The documents may come from teaching and research institutions in France or abroad, or from public or private research centers.
L'archive ouverte pluridisciplinaire HAL, est destinée au dépôt et à la diffusion de documents scientifiques de niveau recherche, publiés ou non, émanant des établissements d'enseignement et de recherche français ou étrangers, des laboratoires publics ou privés. 
This document is confidential and is proprietary to the American Chemical Society and its authors. Do not copy or disclose without written permission. If you have received this item in error, notify the sender and delete all copies.

\section{Effect of the Ligand Binding Strength on the Morphology of Functionalized Gold Nanoparticles}

\begin{tabular}{|r|l|}
\hline Journal: & The Journal of Physical Chemistry Letters \\
\hline Manuscript ID & jz-2020-003008.R1 \\
\hline Manuscript Type: & Letter \\
\hline Complete List of Authors: & n/a \\
\hline & $\begin{array}{l}\text { Chan, Chen-Hui; Ecole normale superieure de Lyon, Laboratoire de } \\
\text { Chimie UMR CNRS 5182 } \\
\text { Poignant, Floriane; Universite Claude Bernard Lyon 1, Institut de } \\
\text { Physique Nucléaire de Lyon } \\
\text { Beuve, Michaël; Universite Claude Bernard Lyon 1, Institut de Physique } \\
\text { Nucléaire de Lyon } \\
\text { Dumont, Elise; Ecole normale superieure de Lyon, Laboratory of } \\
\text { Chemistry } \\
\text { Loffreda, David; LABORATOIRE DE CHIMIE, UMR CNRS 5182, ECOLE } \\
\text { NORMALE SUPERIEURE DE LYON }\end{array}$ \\
\hline
\end{tabular}




\title{
Effect of the Ligand Binding Strength on the Morphology of Functionalized Gold Nanoparticles
}

\author{
Chen-Hui Chan,$\dagger$ Floriane Poignant,+ Michaël Beuve,, Elise Dumont,$\dagger$ and David Loffreda $*, \dagger$ \\ † Univ Lyon, Ens de Lyon, CNRS UMR 5182, Université Claude Bernard Lyon 1, Laboratoire \\ de Chimie, F-69342 Lyon, France. \\ † Univ Lyon, Université Lyon 1, UMR CNRS5822/IN2P3, IPNL, PRISME, PHABIO, \\ Villeurbanne 69322, France.
}

Functionalized gold nanoparticles are investigated by density functional theory calculations in the context of cancer radiotherapy. Several typical experimental shapes including nanostar, nanosphere and nanorod are modeled by optimizing Au clusters covered by organic monolayers composed of hydrated short-chain polyethylene glycol (PEG) ligands. The PEGylation stabilizes significantly the stellation of decahedral $\mathrm{Au}_{54}$ by deforming significantly its geometry at the spikes. The higher stability of the PEG molecules adsorbed on this stellated nanocluster with respect to the more spherical icosahedral $\mathrm{Au}_{55}$ and $\mathrm{Au}_{79}$ leads to a larger energy cost to desorb them and thus a weaker propensity for the starred nanoparticle to exchange ligands with the cell membrane, in agreement with experiments. These results open interesting perspectives for advancing on the understanding of the cellular uptake of gold nanoparticles. 


\section{TOC GRAPHICS}

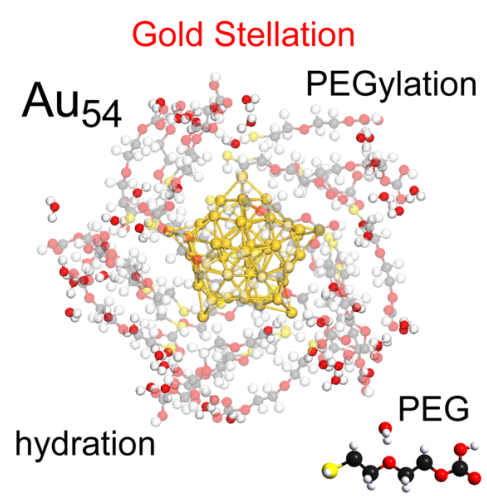

KEYWORDS: Gold nanoparticles, Stellation, PEGylation, Hydration, Density functional theory.

Controlling the size, the shape and the functionalization of gold nanoparticles (GNPs) is essential for nanomedicine and notably in the context of cancer treatment and radiotherapy. ${ }^{1}$ In fact, radiosensitization measured on GNPs coated by organic molecules is a promising approach for improving radiotherapy through water radiolysis enhancing the radiation dose. ${ }^{2}$ Understanding the mechanisms responsible for the apoptosis of the targeted cancerous cells in radiotherapy is by far challenging. To date different assumptions are currently examined to advance on this question. At the cell scale, the pathways of endocytosis (internalization of GNPs) can be either investigated experimentally by optical and microscopic techniques ${ }^{3}$ or modeled theoretically by coarse-grained molecular dynamics (CGMD) simulations. ${ }^{4}$ At the molecular scale, the interaction modes between naked or coated GNPs with membrane lipidic bilayers can also be described by atomistic classical force-fields or CGMD. ${ }^{5}$ Among the key factors influencing endocytosis, the morphology and the size of GNPs are of prime importance.

The morphology of GNPs can be modulated by the chemical nature of the organic coating. Various ligands have already been examined to date, such as poly-ethylene glycol (PEG), ${ }^{6,7}$ 
undecane-thiols and amine derivatives, ${ }^{8}$ DNA strands ${ }^{3}$, mercaptobenzoic acid (MBA), ${ }^{9,10}$ as well as uncoated GNPs as references. ${ }^{11}$ Indeed PEG-based ligands have been often considered for applications in imaging and therapy ${ }^{12}$ because of their high stability, biocompatibility, low cytotoxicity, and interesting antibacterial activity. ${ }^{13}$ For instance, thiol-terminated monomethoxy PEG ligands have been considered for synthesizing gold nanostructures with different shapes (gold spherical nanoparticles GNPs, nanospikes GNSs and nanorods GNRs) around $50 \mathrm{~nm} .{ }^{1}$ According to the measurements, ${ }^{1}$ the cellular uptake is increased in the order of GNPs $>$ GNSs $>$ GNRs, in agreement with previous measurements ${ }^{14}$ and dissipative particle dynamics (DPD) simulations. ${ }^{15}$ All the PEGylated GNPs induce enhanced cancerous cell death rates upon X-ray irradiation. However, sensitization enhancement ratios determined by the amount of internalized gold atoms have been found larger for spherical GNPs than other shapes, thus showing the impact of nanoparticle morphology on cancer radiotherapy. ${ }^{1}$ At larger sizes $(80-90 \mathrm{~nm})$ or alternate shapes, other uptake measurements have shown different trends between PEGylated gold nanotriangles, nanorods and nanostars. ${ }^{16}$ CGMD simulations of water-solvated GNPs with various shapes in the range 2-10 $\mathrm{nm}$ demonstrate also alternative conclusions for the cellular uptake efficiency. ${ }^{17}$ PEGfunctionalized dithiolane ligands terminated by either methoxy or carboxy group have been used to synthesize GNPs in the range 2.4-89 nm. ${ }^{18} \mathrm{Up}$ to $16 \mathrm{~nm}$, these GNPs have been found to localize in the cell nucleus, whereas larger NPs have not entered the cell and have been located at their periphery.

From a mechanistic point of view, experimental ESEM/TEM and theoretical CGMD approaches $^{3}$ have recently shown that the cellular uptake occurs through the ligand exchange at the nanoparticle/membrane interface. The physisorbed ligands on the nanoparticle surface have a 
larger ability to exchange with membrane lipidic molecules depending on their adsorption affinity and chain length.

Regarding the theoretical models of coated GNPs, the coordination of alkane-thiols and PEG ligands has been described by classical molecular dynamics, ${ }^{19,20}$ showing that the thickness of the coating is only weakly dependent on the surface ligand density. Hybrid approaches combining force-field molecular dynamics simulations or CGMD with density-functional theory (DFT) allow the investigation of bicomponent self-assembled monolayers (SAM) on gold. ${ }^{21,22}$ To describe more accurately the SAM energetics, DFT calculations are mainly performed on extended model gold surfaces, ${ }^{21,22,23}$ but also on nanosized thiolated gold clusters. ${ }^{24,25,26}$ Due to the difficulty to observe experimentally the interaction between the nanoparticle and the cell membrane, ${ }^{5}$ a few theoretical studies based on DPD, ${ }^{15} \mathrm{CGMD}^{17}$ and on free energy calculation continuum model ${ }^{27}$ have proposed a first description of these interfaces.

Although numerous experimental studies have investigated the shape of PEGylated GNPs, their impact on the nanoparticle ability to internalize the targeted cells and on radiosensitization efficiency, few information is available today regarding the relationship between the PEG coating, the nanoparticle stability and reactivity. For instance, an accurate theoretical description of the stability depending on the size and on the morphology is missing for functionalized gold nanoparticles around $3 \mathrm{~nm}$, although small uncoated GNPs or covered by glutathione (below 2 $\mathrm{nm}$ ) have shown an interesting performance for cancer radiotherapy. ${ }^{28,29,30}$ Regarding the help of theory, as previously exposed, DFT studies explore mainly the interaction between PEG and alkanethiol-based molecules with $\mathrm{Au}$ extended surfaces (a relevant model for really large nanoparticle facets). However, dry or hydrated PEGylated GNPs have not been described accurately from DFT calculations of nanoclusters to date, especially in the targeted range of $3 \mathrm{~nm}$. 
In this work, we explore the influence of PEGylation, the grafted ligand density and the simultaneous hydration on the stability of functionalized gold nanoparticles (49-79 Au atoms) depending on their size (in the range 3.0-3.2 nm), morphology (nanosphere, nanorod, nanostar shapes, relevant for experiment), on the basis of DFT calculations including dispersion (DFT-D3; see section 2 of the Supporting Information (SI) for the methods). An energy decomposition model is proposed to evaluate the binding strength between one PEG ligand and GNPs at various conditions of surface coverage. Our objective is the determination of the role of the PEG ligands on the nanoparticle stability in order to discuss the cellular uptake of the GNPs for therapeutic applications.

The first step is the selection of the gold nanoclusters to build the organic monolayers of PEGylated systems. To discuss the internalization of the GNPs and the ligand exchange with the membrane, ${ }^{3}$ we have elaborated DFT models of gold nanospheres, nanospikes (nanostars) and nanorod, ${ }^{1}$ on the basis of a previous theoretical study investigating uncoated GNPs in the range 1$3.5 \mathrm{~nm} .{ }^{31}$ Due to the inherent limit of $3 \mathrm{D}$ models $\left(5 \times 5 \times 5 \mathrm{~nm}^{3}\right)$ and in order to keep a reasonable vacuum space between coated GNPs and their equivalent periodic images (1.8-3.2 nm), the size of the gold nanoclusters $(1.1-1.3 \mathrm{~nm})$ coated by water and the organic layer (modeled by two ethylene glycol (EG) units of length $1.6 \mathrm{~nm}$, as shown in Figure 1b), is in the range 3.0-3.2 nm, thus within the explored experimental range ${ }^{18}$ of 2.4-89 nm (see section 3.1 of the SI for the justification of the choice of the PEG terminal moities). Five competitive clusters and typical morphologies have been selected (Figure 1a), with the following stability order in vacuum: irregular truncated octahedral $\mathrm{Au}_{79}>$ icosahedral $\mathrm{Au}_{55}>$ ino-decahedral $\mathrm{Au}_{55}>$ decahedral $\mathrm{Au}_{54}>$ Marks-decahedral $\mathrm{Au}_{49} \cdot{ }^{31}$ 
(a) $\mathrm{Au}_{49}$ (marks)
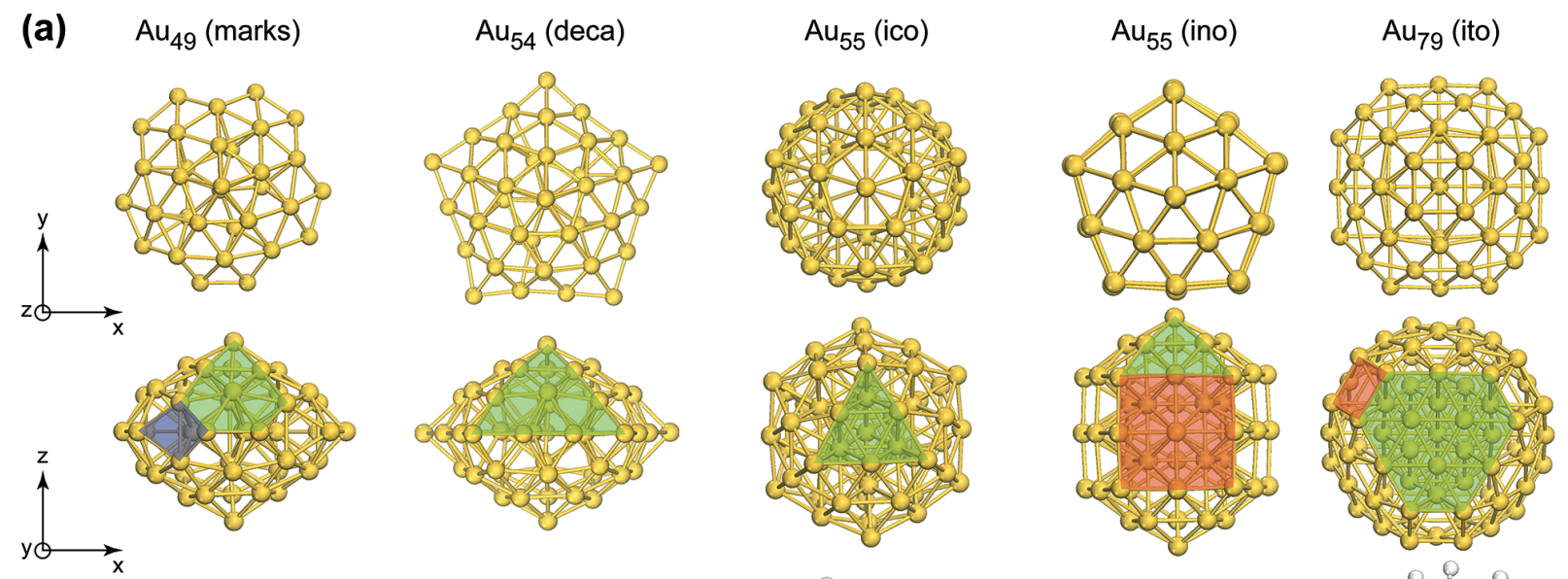

(b)
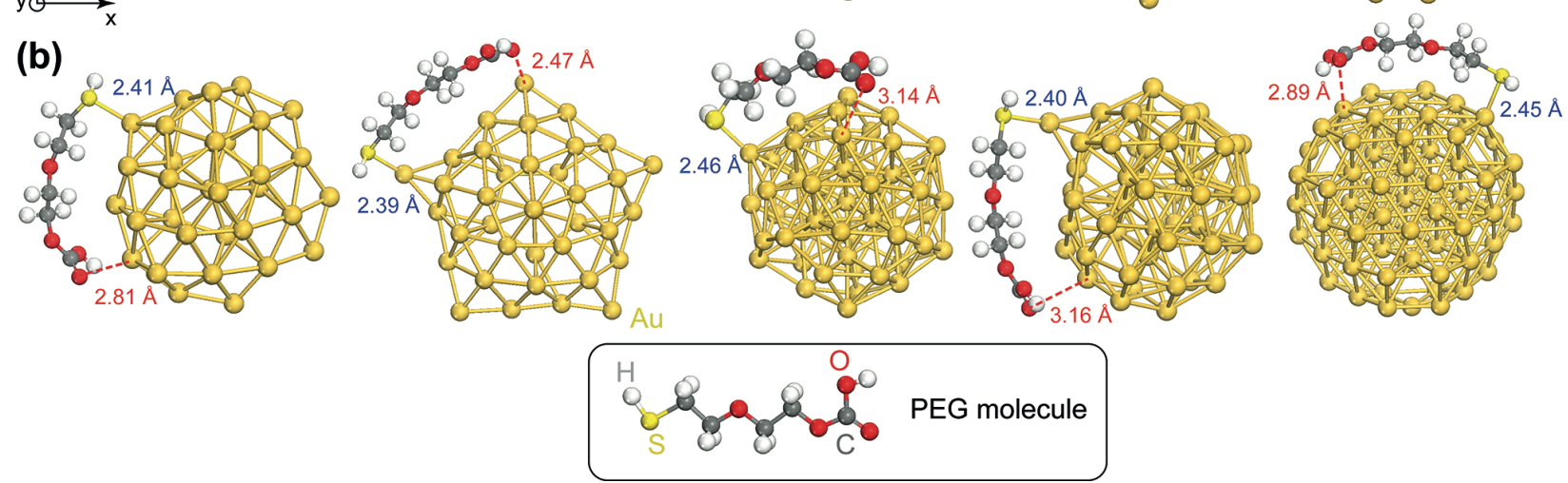

Figure 1. (a) Top and laterals views of optimized clean Au nanoclusters: defective (concave) Marks-decahedral (marks) Au49, regular decahedral (deca) Au54, icosahedral (ico) Aus5, inodecahedral (ino) Au55 and irregular truncated octahedral (ito) Au79. The facet types are marked with colored areas: green for (111)-type (triangle, pentagon or hexagon), red for (100)-type (square) and blue for (110)-type (concavity). (b) Best and optimized adsorption structures $\left(\eta_{2} \mu_{2}\right.$ form) of one PEG molecule (2 EG units, thiol and carboxy terminal groups, trans-conformer) on the five Au nanoclusters. The colors of atom types are defined and will be kept in all the figures.

Before considering the monoshells of PEG ligands surrounding the Au nanoclusters, the most stable isolated adsorption forms have to be investigated for each shape and size. In Figure $1 \mathrm{~b}$ and Table 1, the key results of the best adsorption structures of isolated PEG on the five Au nanoclusters have been reported. 
Table 1. Grafting densities (molec.nm-2) and adsorption energetics of the most stable structures for one PEG molecule on five Au nanoclusters (Figure 1). ${ }^{\mathrm{a}}$

\begin{tabular}{llllll}
\hline 1 PEG & $\mathrm{Au}_{49}$ (marks) & $\mathrm{Au}_{54}(\mathrm{deca})$ & $\mathrm{Au}_{55}$ (ico) & $\mathrm{Au} 55$ (ino) & $\mathrm{Au} 79$ (ito) \\
\hline Grafting density & 0.20 & 0.19 & 0.16 & 0.15 & 0.08 \\
$\Delta \mathrm{E}_{\text {ads }}$ & -1.589 & -1.736 & -1.358 & -1.623 & -1.519 \\
$\Delta \mathrm{E}_{\text {disp }}$ & -0.802 & -0.632 & -0.783 & -0.822 & -0.948 \\
$\Delta \mathrm{E}_{\text {cov }}$ & -0.787 & -1.104 & -0.575 & -0.801 & -0.571 \\
$\Delta \mathrm{E}_{\text {def AuNP }}$ & 0.044 & 0.045 & 0.043 & 0.057 & 0.066 \\
$\Delta \mathrm{E}_{\text {def PEG }}$ & 0.178 & 0.093 & 0.125 & 0.076 & 0.098 \\
$\Delta \mathrm{E}_{\text {int PEG-Au }}$ & -1.810 & -1.874 & -1.526 & -1.756 & -1.683
\end{tabular}

${ }^{a}$ Adsorption energy $\Delta \mathrm{E}_{\text {ads }}(\mathrm{eV})$, decomposed into dispersion $\Delta \mathrm{E}_{\text {disp }}(\mathrm{eV})$ and pure GGA $\Delta \mathrm{E}_{\text {cov }}$ $(\mathrm{eV})$ contributions, or into deformation energy of $\mathrm{Au}, \Delta \mathrm{E}_{\mathrm{def}} \mathrm{AuNP}$, of PEG, $\Delta \mathrm{E}_{\mathrm{def}} \mathrm{PEG}(\mathrm{eV})$ and interaction energy between PEG and $\mathrm{Au}, \Delta \mathrm{E}_{\text {int }} \mathrm{PEG}-\mathrm{Au}(\mathrm{eV})$ (chemical bonding). See the SI for all the definitions and corresponding equations.

In the SI, all the optimized stable and metastable forms are presented with adsorption energies and key distances (see eq S2 of the SI and Figures S1-S5). Due to the terminal -SH and -COOH moieties of PEG and the various adsorption sites on Au nanoclusters (kink, edge, facet), there exist many adsorption structures. Since $\mathrm{S}$ atom is more strongly bound to $\mathrm{Au}(111)$ than $\mathrm{COOH},{ }^{32}$ the adsorption of PEG on Au nanoclusters has been mainly built through -SH moiety (with a short distance in the range 2.39-2.46 $\AA$, see Figure 1b). However, for isolated chemisorption, an additional stabilizing interaction between $-\mathrm{COOH}($ via $-\mathrm{C}=\mathrm{O})$ and $\mathrm{Au}$ is obtained (with a longer distance in the range 2.47-3.16 $\AA$ ). According to the best adsorption structures, SH terminal group is always bound on a nanoparticle kink, while $\mathrm{COOH}$ moiety can interact with a nanoparticle kink or an edge, leading to $\eta_{2} \mu_{2}$ new adsorption forms with respect to the literature. ${ }^{21,22,33,34}$ The adsorption energy is the largest one on $\mathrm{Au}_{54}$ (deca) $(-1.736 \mathrm{eV}$, Table 1), for which the distortion of the gold nanocluster is significant with an extraction of the interacting Au kink atom from its 
epitaxial position and a beginning of stellation for the nanoparticle. The adsorption strength magnitude $(1.358-1.736 \mathrm{eV})$ is compatible with previous theoretical works for alkanethiols on $\mathrm{Au}_{20}(-1.16 \mathrm{eV})$ and $\mathrm{Au}(111)(-1.54 \mathrm{eV}) .{ }^{33,34}$ The adsorption of PEG on $\mathrm{Au}_{55}$ (ino) is the second best form $(-1.623 \mathrm{eV})$ which results in a strong deformation of the nanorod shape (ino-decahedron) where the (100) facets transform into (111)-type orientations (icosahedron). For the three other $\mathrm{Au}$ nanoclusters, the adsorption energy is weaker and the gold shape resembles the initial symmetric morphology. Due to the simultaneous bonds between the two terminal functions and gold, the PEG ligand tends to bend over the Au nanocluster, in order to optimize the van der Waals forces. This can be understood by the energy decomposition of the adsorption energy into pure-GGA (covalence) and dispersion energetic terms which are predominant, except for $\mathrm{Au}_{54}$ (deca) (Table 1 and eq S3 in the SI). Alternatively, the energy decomposition analysis ${ }^{35}$ (EDA) (see eq S9 of the SI and Table 1) splits the adsorption energy into destabilizing (positive) and minority deformation energies (PEG ligand and Au nanocluster) and stabilizing (negative) and predominant interaction energies between PEG and Au (chemical bonding). The deformation energies of Au (calculated from the optimal deformed Au nanoclusters related to adsorption structures) are also weak for $\mathrm{Au}_{54}$ (deca) and $\mathrm{Au}_{55}$ (ino), although the geometric distortion is large with respect to the initial symmetric clusters (see section 3.6 of the SI for more details).

Once the most stable chemisorption forms of one PEG molecule are known, an organic coating composed of monoshells of PEG ligands surrounding the five Au nanoclusters has been built with a surface density approaching saturation (Figure 2). Due to the difference of surface area and accessible surface Au atoms between all these clusters, the PEG surface (grafting) density varies from one cluster to another one. According to experiments, ${ }^{36,37,38}$ the ligand grafting density decreases with the diameter of the nanoparticle and the ligand molecular weight. 
(a)

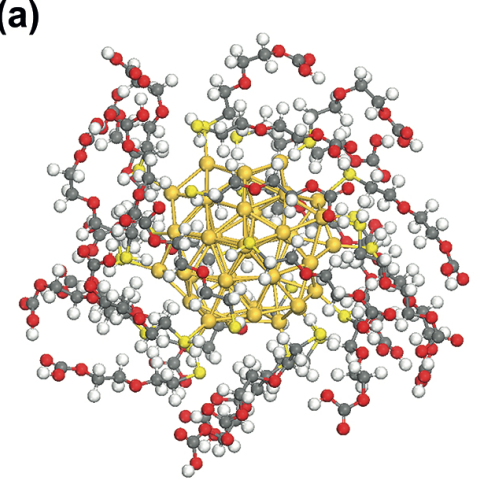

$\mathrm{Au}_{49}$ (marks)

26 PEG

$\mathrm{N}_{\mathrm{c}}=17 ; \mathrm{N}_{\mathrm{p}}=9$

$\theta_{\text {chem }}=0.41 \mathrm{ML}$

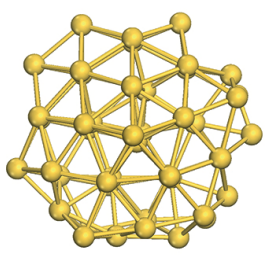

(b)
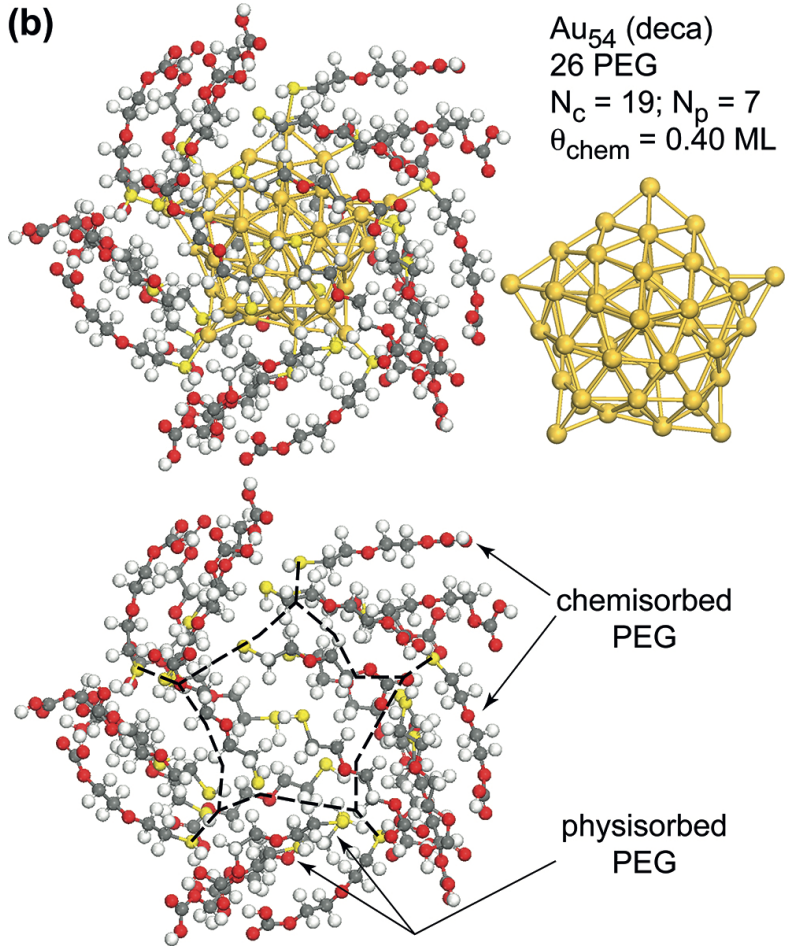

$\mathrm{Au}_{54}$ (deca)

26 PEG

$\mathrm{N}_{\mathrm{c}}=19 ; \mathrm{N}_{\mathrm{p}}=7$

$\theta_{\text {chem }}=0.40 \mathrm{ML}$ (c)

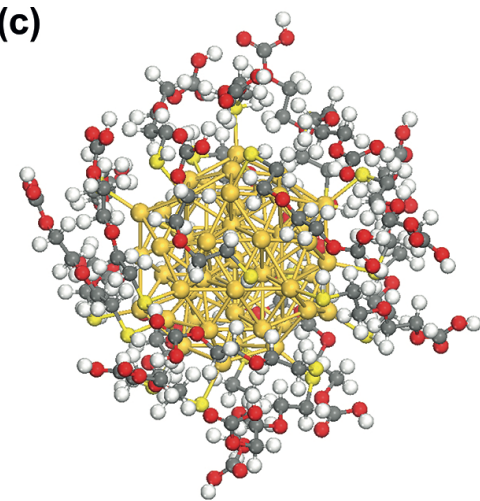

$\mathrm{Au}_{55}$ (ico)

22 PEG

$\mathrm{N}_{\mathrm{c}}=19 ; \mathrm{N}_{\mathrm{p}}=3$

$\theta_{\text {chem }}=0.45 \mathrm{ML}$

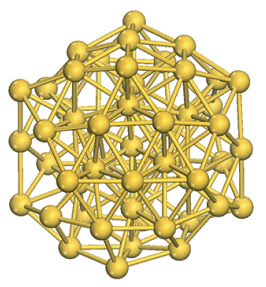

(d)

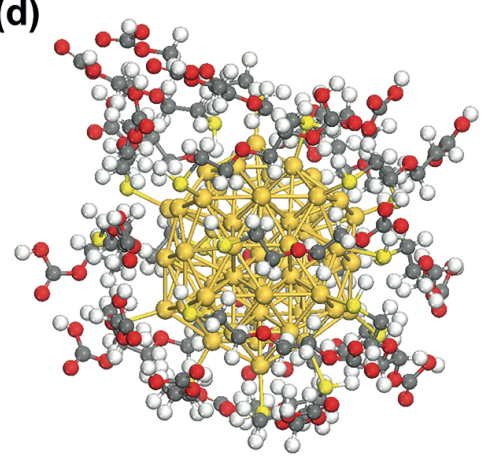

$\mathrm{Au}_{55}$ (ino)

22 PEG

$\mathrm{N}_{\mathrm{c}}=18 ; \mathrm{N}_{\mathrm{p}}=4$

$\theta_{\text {chem }}=0.43 \mathrm{ML}$

(e)

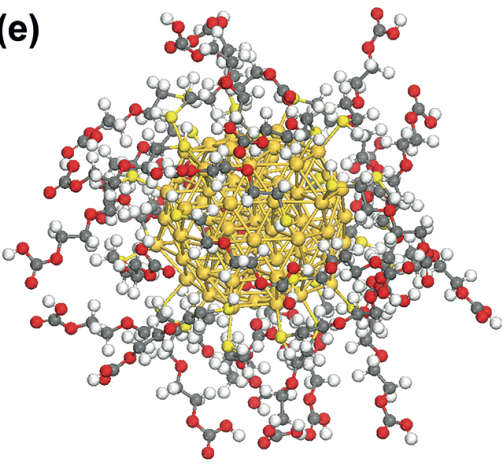

Figure 2. Optimized PEGylated Au nanoclusters with monoshells of adsorbed molecules close to saturation : (a) Marks-decahedral Au49, (b) stellated decahedral Aus4, (c) icosahedral Au55, (d) initially ino-decahedral $\mathrm{Au}_{55}$ (transformed into icosahedral $\mathrm{Au}_{55}$ ) and (e) irregular truncated octahedral Au79. Distorted geometries of Au clusters (without PEG) are also presented. For each system the numbers of PEG ligands in the organic coating, of chemisorbed $\left(\mathrm{N}_{\mathrm{c}}\right)$ and physisorbed $\left(\mathrm{N}_{\mathrm{p}}\right)$ molecules, the surface coverage $\theta_{\text {chem }}$ related to chemisorbates $(\mathrm{ML}=$ monolayer) are mentioned. The stellation $\left(\mathrm{Au}_{54}\right)$ results in a more organized coating ("brushed-type"), whereas non symmetric deformation ( $\mathrm{Au}_{49}, \mathrm{Au}_{55}$ and $\left.\mathrm{Au}_{79}\right)$ induces disordered monoshells ("bushy-type"). 
For small $\mathrm{GNPs}^{37}(<5 \mathrm{~nm})$, grafting densities exceed 1.6 chains.nm ${ }^{-2}$. Moreover, for short chain ligand $\left(<1000 \mathrm{~g}^{\mathrm{mol}} \mathrm{m}^{-1}\right)$, the densities become larger than 2.5 chains.nm ${ }^{-2}\left(3.2-3.9\right.$ chains.nm ${ }^{-2}$ for specific PEG ligands ${ }^{36,38}$ ). The molecular weights and number of ligands on the GNPs have also a significant influence on their orientations around gold, ${ }^{38}$ giving rise to a transition from disorganized "mushroom" orientations to more rigid "brush" configurations. In our case, depending on the Au nanocluster, the explored range is 2.7-5.1 molec.nm ${ }^{-2}$ (Table 2), in fair agreement with the literature. ${ }^{21,36,38}$ Although the molecule surface density changes significantly, the surface coverage normalized to the number of surface $\mathrm{Au}$ atoms, is equivalent for all the GNPs, in the range $0.40-0.45 \mathrm{ML}(<0.5$ monolayer $)$.

Table 2. Grafting densities (molec.nm ${ }^{-2}$ ) and adsorption energetics of the five non hydrated PEGylated Au nanoclusters (Figure 2). ${ }^{\mathrm{a}}$

\begin{tabular}{|c|c|c|c|c|c|}
\hline $\mathrm{PEG}_{\text {sat }}$ & $\mathrm{Au}_{49}$ (marks) & $\mathrm{Au}_{54}(\mathrm{deca})$ & $\mathrm{Au}_{55}$ (ico) & $\mathrm{Au}_{55}$ (ino) & $\mathrm{Au}_{79}$ (ito) \\
\hline Grafting density & 5.09 & 4.87 & 3.44 & 3.24 & 2.66 \\
\hline$\Delta \mathrm{E}_{\text {coads }}\left(/ \mathrm{PEG}_{\text {chem }}\right)$ & -1.933 & -1.719 & -1.565 & -1.569 & -1.471 \\
\hline$\Delta \mathrm{E}_{\text {disp }}\left(/ \mathrm{PEG}_{\mathrm{tot}}\right)$ & -0.754 & -0.780 & -0.815 & -0.791 & -0.783 \\
\hline$\Delta \mathrm{E}_{\mathrm{cov}}\left(/ \mathrm{PEG}_{\mathrm{tot}}\right)$ & -1.180 & -0.938 & -0.750 & -0.778 & -0.689 \\
\hline$\Delta \mathrm{E}_{\text {int PEG-Au }}\left(/ \mathrm{PEG}_{\text {chem }}\right)$ & -1.269 & -1.200 & -1.092 & -1.224 & -1.053 \\
\hline$\Delta \mathrm{E}_{\mathrm{def}} \mathrm{AuNP}$ (non normalized) & 1.851 & 2.362 & 0.884 & 2.205 & 2.479 \\
\hline$\Delta \mathrm{E}_{\text {def }}$ int PEG-PEG $\left(/ \mathrm{PEG}_{\mathrm{tot}}\right)$ & -0.506 & -0.470 & -0.449 & -0.382 & -0.430 \\
\hline
\end{tabular}

${ }^{\mathrm{a}}$ Coadsorption energy $\Delta \mathrm{E}_{\text {coads }}(\mathrm{eV}$ per chemisorbed $\mathrm{PEG})$, decomposed into dispersion $\Delta \mathrm{E}_{\text {disp }}(\mathrm{eV}$ per PEG ligand) and pure GGA $\Delta \mathrm{E}_{\text {cov }}$ (eV per PEG ligand) contributions, or into deformation energy of $\mathrm{Au}, \Delta \mathrm{E}_{\text {def }} \mathrm{AuNP}$ (non normalized), of PEG summed with the PEG-PEG intermolecular interaction energy, $\Delta \mathrm{E}_{\text {def }+ \text { int }}$ PEG-PEG ( $\mathrm{eV}$ per PEG ligand) and into interaction energy between PEG and $\mathrm{Au}, \Delta \mathrm{E}_{\text {int }}$ PEG-Au $(\mathrm{eV}$ per chemisorbed PEG). See the SI for definitions and equations. 
In order to reach the organic monolayer on GNPs, the clusters have been decorated by maximizing the best adsorption forms found previously for isolated PEG, and by completing the organic coating with metastable structures. The optimal PEG monoshells on GNPs have been addressed in Figure 2 and corresponding energetics in Table 2. From a geometrical point of view, the PEGylated GNPs exhibit different ligand organization from one cluster to another one. In the case of the decahedral shapes ( $\mathrm{Au}_{49}$ (marks) and $\left.\mathrm{Au}_{54}(\mathrm{deca})\right)$, the ligand arrangements are more symmetric "brushed-type" (Figure 2a,b), whereas the icosahedral and octahedral clusters $\left(\mathrm{Au}_{55}\right.$ (ico) and $\mathrm{Au}_{79}$ (ito)) are decorated by a more disordered "bushy-type" coating (Figure 2c,d,e).

Moreover, the deformation of the metallic nanoclusters has significantly increased with respect to the isolated adsorption. In the case of $\mathrm{Au}_{55}$ (ino), the nanorod initial morphology of inodecahedron is entirely lost in favor of an icosahedron (Figure 2d). In addition, the stellation induced by the PEG coating on $\mathrm{Au}_{54}$ (deca) is remarkably strong (Figure 2b). The PEG ligands separate during the geometry optimizations in two different adsorption families: majority chemisorbed molecules bound through -SH groups to gold and minority physisorbed ligands inside the organic coating bound with other ligands via hydrogen bonds and van der Waals interactions (Figure 2b). The hydrogen bonds can also stabilize cochemisorbed PEG molecules and help the brushed configuration for $\mathrm{Au}_{54}$ (deca). From an energetic standpoint (Table 2), the coadsorption energy per PEG molecule of the PEGylated GNPs is globally similar to the previous adsorption energy values for isolated chemisorption. However, it can be either larger ( $\mathrm{Au}_{49}$ (marks) and $\mathrm{Au}_{55}$ (ico)) or smaller ( $\mathrm{Au}_{54}$ (deca), $\mathrm{Au}_{55}$ (ino) and $\mathrm{Au}_{79}$ (ito)) due to the lateral interactions between ligands (lateral effect) and the competition for interacting with the electronic density of gold nanoclusters (coverage effect). For the case of $\mathrm{Au}_{55}$ (ino) and (ico), the coadsorption energy per PEG is identical since the ino-decahedron is transformed into icosahedron as explained before. 
Close to ligand saturation, the dispersion energy is slightly more stabilizing than the pure GGA contribution, except, once again, for the systems having the largest coadsorption energy (Au49 (marks) and $\mathrm{Au}_{54}($ deca)). According to the EDA, the interaction energy between PEG and Au nanoclusters per PEG ligand (eq S19 of the SI and Figure S10) is globally weakened in the monoshells by comparison with the isolated adsorption (coverage effect). Surprisingly, the deformation energy of the Au clusters is very large and maximal for Aus4 (deca) (2.362 eV) and $\mathrm{Au}_{79}$ (ito) $(2.479 \mathrm{eV})$, in relation with a significant displacement of all the gold atoms with respect to their initial symmetric positions (Figure 2). Hence the distorted geometry of Au in the optimal structures including the PEG ligands is not stable anymore, at the opposite of the isolated chemisorption. In the case of $\mathrm{Au}_{54}$ (deca), a stellated cluster is obtained by forming spikes with the five corners of the pentagonal structure. The global energetic loss coming from the concomitant weakened PEG-Au interaction energy and increased Au deformation energy is balanced by the stabilizing intermolecular interaction energy between the PEG ligands (from -0.382 to $-0.506 \mathrm{eV}$ per molecule). This energetic term (eq S24 of the SI and Figure S11) is the resulting contribution of weak destabilizing PEG deformation energy and significantly stabilizing dispersion forces and hydrogen bonds between molecules. Hence the apparently unstable stellation (in vacuum) and other deformations of gold structure are promoted by the monoshells of PEG ligands, especially by the lateral molecular interactions. A similar study and analysis are proposed for hydrated PEGylated gold nanoparticles (see sections 3.4 and 3.7.3 of the SI for all the details and results).

Once the structural and energetic properties of PEGylated GNPs have been described, the next steps are the understanding of the role of the PEG ligand on the stability and the morphology of $\mathrm{Au}$ nanoclusters and the determination of the relationship between the coated GNP stability and their use in radiotherapy. 
According to the energetic analysis of PEGylated GNPs, PEG ligands promote the stellation of regular decahedral shape $\left(\mathrm{Au}_{54}(\mathrm{deca})\right)$. In order to quantify this result, the absolute stability of the coated GNPs is evaluated by the formation surface energy $\Gamma_{\text {form }}$ obtained by generating the $\mathrm{Au}$ nanocluster from isolated Au atoms and by coadsorbing PEG molecules and water, and normalized by the relaxed surface area of the Au cluster. In Figure $3, \Gamma_{\text {form }}$ is plotted against the molecule surface density calculated by dividing the number of adsorbed PEG ligands by the nanoparticle area. Clearly, the stellated decahedral-based $\mathrm{Au}_{54}$ cluster is by far the most stable one in all the considered cases (isolated PEG adsorption, Figure 3a, non hydrated and hydrated PEG coadsorption, Figure $3 b)$. The intrinsic stability of the cluster increases almost linearly with the molecule surface density, and inversely with respect to the nanoparticle size, by following the order: $\mathrm{Au}_{54}($ deca $)>\mathrm{Au}_{55}\left(\right.$ ico) $>\mathrm{Au}_{79}$ (ito). This counter-intuitive trend is just the opposite of the one calculated in vacuum. The case of $\mathrm{Au}_{49}$ (marks) is an exception with respect to this trend in term of size. This is explained by the decrease of the nanocluster area related to the presence of concavities (defects in the Marks-decahedral shape) by comparison with $\mathrm{Au}_{54}$ (deca), thus inducing an increase of the molecule surface density (Table 2).

A relationship between the ligand binding strength in GNPs and their ability to internalize in the cell (endocytosis) for radiotherapeutic applications can be established since the cellular uptake has been recently correlated with the physisorbed ligand exchange at the nanoparticle/membrane interface $^{3}$ (the cellular uptake increasing in the order of nanospheres $>$ nanospikes $>$ nanorods ${ }^{1}$ ). For spherical and starred GNPs, the energy cost to desorb one ligand can be evaluated by the opposite of the coadsorption energy per PEG ligand (non-activated process). This is a good approximation of the ligand exchange with the lipidic membrane since the final state (ligand grafted on the membrane) does not really depend on the nature of the GNP. In addition, a previous 
theoretical study of protonated thiol-thiol exchange over aromatic thiolate protected $\mathrm{GNPs}^{25}$ has demonstrated that the overall activation barrier for the exchange with methane thiol is moderate (23 kcal.mol-1) and corresponds mainly to the desorption step of the $\mathrm{H}_{2} \mathrm{~S}$ product $\left(18 \mathrm{kcal} . \mathrm{mol}^{-1}\right)$, thus justifying our approximation.

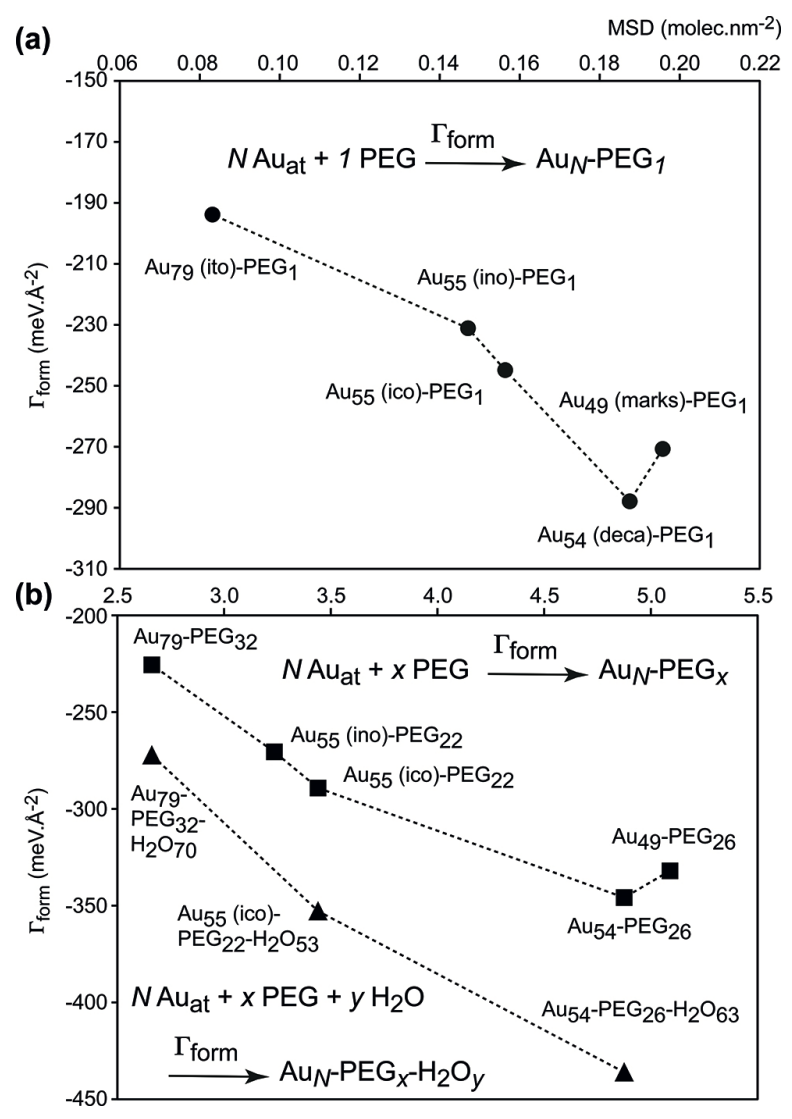

Figure 3. Formation energy $\Gamma_{\text {form }}$ expressed in surface energy per particle unit area $\left(\mathrm{meV} . \AA^{-2}\right)$ of GNPs plotted against the PEG molecule surface density (MSD) (molec.nm-2). (a) Isolated adsorption of a PEG on five typical Au nanoclusters. (b) (top) PEGylated GNPs (SAM) for the five Au clusters and (bottom) hydrated PEGylated GNPs for the three competitive shapes. The chemical equations are indicated for the corresponding definitions of $\Gamma_{\text {form. }}$.

According to the coadsorption energies for non-hydrated GNPs (Table 2), the energy cost to desorb one PEG ligand is maximal for the starred $\mathrm{Au}_{54}$ (deca) GNP, thus meaning that the ligand 
exchange will be easier for the more spherical $\mathrm{Au}_{55}$ (ico) and Au79 (ito) GNPs (due to a weaker interaction energy between one PEG ligand and $\mathrm{Au}$ ). Hence the cellular uptake is expected to be larger for more spherical morphologies such as icosahedral $\left(\mathrm{Au}_{55}\right)$ and octahedral $\left(\mathrm{Au}_{79}\right)$ shapes than for the stellated decahedral one $\left(\mathrm{Au}_{54}\right)$. Our result agrees with measurements ${ }^{1}$ and brings a first element of explanation. The trend is identical for hydrated PEGylated GNPs (see section 3.8 of the SI).

The PEGylation of several sizes and morphologies of gold nanoparticles has been explored on the basis of density functional theory calculations in the range 3.0-3.2 $\mathrm{nm}$. The stellation of the decahedral nanocluster $\mathrm{Au}_{54}$ has been demonstrated and explained by the particular stability of the PEG ligands through stabilizing interactions energies between PEG and Au and between PEG chains (hydrogen bonds). A relation could have been established between the stability of the coated gold clusters and their uptake inside the cell. Due to the larger stability of the PEG chains in the case of the stellated PEGylated $\mathrm{Au}_{54}$ cluster, the energy cost to exchange a PEG ligand with the membrane is expected to be higher than the one predicted for more spherical icosahedral $\mathrm{Au}_{55}$ and truncated octahedral $\mathrm{Au}_{79}$ clusters. This counterintuitive result is in fair agreement with measurements provided for much larger gold aggregates. In summary our atomistic results pave the way to the parametrization of multiscale approaches including coarse-grained molecular dynamics and Monte Carlo simulations aiming to investigate the interaction of GNPs with the cell membrane as a function of their morphology, in the context of the cancerous cell apoptosis. 


\section{ASSOCIATED CONTENT}

Supporting Information. After addressing methods and model hypotheses, we expose all the optimized adsorption structures of one PEG on different top sites of various GNPs (Figures S1S5); the optimized structures of hydrated PEGylated GNPs (Figure S6); the optimized structures of several uncoated GNPs (Figure S7); the stability diagram of optimal GNPs against the chemical environment (Figure S8); the analysis of roundness degree variation of GNPs (Figure S9). All the definitions of the normalized interaction energy between GNPs, PEG ligands and $\mathrm{H}_{2} \mathrm{O}$ molecules are reported (Figures S10-S23). The families of water molecules hydrating the PEG organic layers in GNPs are defined in Figure S24. The optimal dimerization structures between one PEG and one water molecule are presented (Figure S25). The formula to evaluate the nanoparticle areas are given in Table S1; the energetics of hydrated PEGylated GNPs in Table S2; the ligand extraction energy analysis for the hydrated PEGylated GNPs in Table S3; the energy decomposition analysis of the hydrated PEGylated Au nanoclusters in Table S4. The definitions of cohesion energy, adsorption energy, covalence and dispersion energies, roundness degree are addressed in eqs S1S7. The energy decomposition analyses for an isolated adsorbed PEG molecule, monoshells of PEGylated GNPs, monoshells of hydrated PEGylated GNPs are defined in eqs S8-S64. The definition of the number of hydrogen bonds for hydrated PEGylated GNPs is given in eq S65.

\section{AUTHOR INFORMATION}

\section{Corresponding Author}

* E-mail: david.loffreda@ens-lyon.fr

\section{ORCID}

David Loffreda : 0000-0001-9912-7965. 


\begin{abstract}
Notes
The authors declare no competing financial interests.
\end{abstract}

Chen-Hui Chan has performed all the DFT calculations of the PEGylated and hydrated gold nanoparticles with VASP package. David Loffreda has performed DFT calculations of naked gold nanoparticles with VASP package. Elise Dumont has written the proposal and applied to the LABEX PRIMES call to be funded. Floriane Poignant and Michaël Beuve have contributed to the scientific discussions related to the applications in radiotherapy. All the authors have contributed to the writing of the manuscript and have given approval to its final version.

\title{
ACKNOWLEDGMENT
}

The authors thank IDRIS in Paris, CINES in Montpellier, TGCC in Grenoble (project 609, GENCI/CT8) and PSMN in Lyon for CPU time and assistance. Chen-Hui Chan and Floriane Poignant thank LABEX PRIMES (ANR-11-LABX-0063) of Université de Lyon (within the program "Investissements d'Avenir" ANR-11-IDEX-0007) for the PhD funding. Floriane Poignant thanks « Fondation ARC pour la recherche sur le cancer » for the support. The authors thank the CPER/SYSPROD 2015-2022 project (N²019-AURA-P5B) and AXELERA Pôle de Compétitivité for financial support (PSMN Data Center). 


\section{REFERENCES}

(1) Ma, N.; Wu, F. G.; Zhang, X.; Jiang, Y. W.; Jia, H. R.; Wang, H. Y.; Jia, H. R.; Li, Y.H.; Liu, P.; Gu, N.; Chen, Z. Shape-Dependent Radiosensitization Effect of Gold Nanostructures in Cancer Radiotherapy: Comparison of Gold Nanoparticles, Nanospikes and Nanorods. ACS Appl. Mater. Interfaces 2017, 9, 13037-13048. DOI: 10.1021/acsami.7b01112.

(2) Peukert, D.; Kempson, I.; Douglass, M.; Bezak, E. Metallic Nanoparticle Radiosensitisation of Ion Radiotherapy: a Review. Physica Medica 2018, 47, 121-128, DOI: 10.1016/j.ejmp.2018.03.004.

(3) Wang, X.; Wang, X.; Bai, X.; Yan, L.; Liu, T.; Wang, M.; Song, Y.; Hu, G.; Gu, Z.; Miao, Q.; Chen, C. Nanoparticle Ligand Exchange and Its Effects at the Nanoparticle-Cell Membrane Interface. Nano Lett. 2019, 19, 8-18. DOI: 10.1021/acs.nanolett.8b02638.

(4) Zhang, S.; Gao, H.; Bao, G. Physical Principles of Nanoparticle Cellular Endocytosis. ACS Nano 2015, 9, 8655-8671. DOI: 10.1021/acsnano.5b03184.

(5) Manning, M. D.; Kwansa, A. L.; Oweida, T.; Peerless, J. S.; Singh, A.; Yingling, Y. G. Progress in Ligand Design for Monolayer-protected Nanoparticles for Nanobio Interfaces. Biointerphases 2018, 13, 06D502. DOI: 10.1116/1.5044381.

(6) Zhang, X. D.; Wu, D., Shen, X.; Chen, J.; Sun, Y. M.; Liu, P. X.; Liang, X. J. Size-dependent Radiosensitization of PEG-coated Gold Nanoparticles for Cancer Radiation Therapy. Biomaterials 2012, 33, 6408-6419. DOI: 10.1016/j.biomaterials.2012.05.047. 
(7) Gilles, M.; Brun, E.; Sicard-Roselli, C. Gold Nanoparticles Functionalization Notably Decreases Radiosensitization Through Hydroxyl Radical Production under Ionizing Radiation. Colloids Surf B Biointerfaces 2014, 123, 770-777. DOI: 10.1016/j.colsurfb.2014.10.028.

(8) Xiao, F.; Zheng, Y.; Cloutier, P.; He, Y.; Hunting, D.; Sanche, L. On the Role of Low-energy Electrons in the Radiosensitization of DNA by Gold Nanoparticles. Nanotechnology 2011, 22, 465101. DOI: 10.1088/0957-4484/22/46/465101.

(9) Jadzinsky, P. D. ; Calero, G.; Ackerson, C. J.; Bushnell, D. A.; Kornberg, R. D. Structure of a Thiol Monolayer-Protected Gold Nanoparticle at 1.1 Å Resolution. Science 2007, 318, 430-433. DOI: $10.1126 /$ science.1148624.

(10) Azubel, M.; Leen Koh, A.; Koyasu, K.; Tsukuda, T.; Kornberg, R. D. Structure Determination of a Water-Soluble 144-Gold Atom Particle at Atomic Resolution by AberrationCorrected Electron Microscopy. ACS Nano 2017, 11, 11866-11871. DOI: 10.1021/acsnano.7b06051.

(11) Rahman, W. N.; Bishara, N.; Ackerly, T.; He, C. F.; Jackson, P.; Wong, C.; Davidson, R.; Geso, M. Enhancement of Radiation Effects by Gold Nanoparticles for Superficial Radiation Therapy. Nanomedicine 2009, 5, 136-142. DOI: 10.1016/j.nano.2009.01.014.

(12) Jokerst, J. V.; Lobovkina, T.; Zare, R. N.; Gambhir, S. S. Nanoparticle PEGylation for Imaging and Therapy. Nanomedicine 2011, 6, 715-728. DOI: 10.2217/nnm.11.19.

(13) Reznickova, A.; Slavikova, N.; Kolska, Z.; Kolarova, K.; Belinova, T.; Kalbacova, M. H.; Belinova, T.; Hubalek Kalbacova, M.; Cieslar, M.; Svorcik, V. PEGylated Gold Nanoparticles: 
Stability, Cytotoxicity and Antibacterial Activity. Colloids Surf., A 2019, 560, 26-34. DOI: 10.1016/j.colsurfa.2018.09.083.

(14) Wang, Y.; Black, K. C.; Luehmann, H.; Li, W.; Zhang, Y.; Cai, X.; Wan, D.; Liu, S.; Li, M.; Kim, P.; Li, Z. Y.; Wang, L. V.; Liu, Y.; Xia, Y. Comparison Study of Gold Nanohexapods, Nanorods, and Nanocages for Photothermal Cancer Treatment. ACS Nano 2013, 7, 2068-2077. DOI: $10.1021 / \mathrm{nn} 304332$ s.

(15) Li, Y.; Kröger, M.; Liu, W. K. Shape Effect in Cellular Uptake of PEGylated Nanoparticles: Comparison between Sphere, Rod, Cube and Disk. Nanoscale 2015, 7, 16631-16646. DOI: $10.1039 / \mathrm{c} 5 \mathrm{nr} 02970 \mathrm{~h}$

(16) Xie, X.; Liao, J.; Shao, X.; Li, Q.; Lin, Y. The Effect of Shape on Cellular Uptake of Gold Nanoparticles in the Forms of Stars, Rods, and Triangles. Sci. Rep. 2017, 7, 3827. DOI: 10.1038/s41598-017-04229-Z.

(17) Lunnoo, T.; Assawakhajornsak, J.; Puangmali, T. In Silico Study of Gold Nanoparticle Uptake into a Mammalian Cell: Interplay of Size, Shape, Surface Charge, and Aggregation. J. Phys. Chem. C 2019, 123, 3801-3810. DOI: 10.1021/acs.jpcc.8b07616.

(18) Oh, E.; Delehanty, J. B.; Sapsford, K. E.; Susumu, K.; Goswami, R.; Blanco-Canosa, J. B.; Dawson, P. E.; Granek, J.; Shoff, M.; Zhang, Q. L.; Goering, P.; Huston, A.; Goering, P. L. Cellular Uptake and Fate of PEGylated Gold Nanoparticles is Dependent on Both Cell-penetration Peptides and Particle size. ACS Nano 2011, 5, 6434-6448. DOI: 10.1021/nn201624c.

(19) Haume, K.; Mason, N. J.; Solov'yov, A. V. Modeling of Nanoparticle Coatings for Medical Applications. Eur. Phys. J. D 2016, 70, 181. DOI: 10.1140/epjd/e2016-70282-6. 
(20) Pohjolainen, E. ; Chen, X. ; Malola, S. ; Groenhof, G. ; Häkkinen, H. A Unified AMBERCompatible Molecular Mechanics Force Field for Thiolate-Protected Gold Nanoclusters. J. Chem. Theory Comput. 2016, 12, 1342-1350. DOI: 10.1021/acs.jctc.5b01053.

(21) Meena, S. K.; Goldmann, C.; Nassoko, D.; Seydou, M.; Marchandier, T.; Moldovan, S.; Ersen, O., Ribot, F.; Chaneac, C.; Sanchez, C.; Portehault, D. Tielens, F.; Sulpizi, M. Nanophase Segregation of Self-assembled Monolayers on Gold Nanoparticles. ACS Nano 2017, 11, 73717381. DOI: $10.1021 /$ acsnano.7b03616.

(22) Gao, H. M.; Liu, H.; Qian, H. J.; Jiao, G. S.; Lu, Z. Y. Multiscale Simulations of Ligand Adsorption and Exchange on Gold Nanoparticles. Phys. Chem. Chem. Phys. 2018, 20, 1381-1394. DOI: 10.1039/C7CP07039J.

(23) Goldmann, C.; Ribot, F.; Peiretti, L. F.; Quaino, P.; Tielens, F.; Sanchez, C.; Chaneac, C.; Portehault, D. Quantified Binding Scale of Competing Ligands at the Surface of Gold Nanoparticles: The Role of Entropy and Intermolecular Forces. Small 2017, 13, 1604028. DOI: 10.1002/smll.201604028.

(24) Häkkinen, H. The Gold-Sulphur Interface at the Nanoscale. Nat. Chem. 2012, 4, 443-455. DOI: $10.1038 /$ NCHEM.1352

(25) Heinecke, C. L.; Ni, T. W. ; Malola, S. ; Mäkinen, V. ; Wong, A. O.; Häkkinen, H.; Ackerson, C. J Structural and Theoretical Basis for Ligand Exchange on Thiolate Monolayer Protected Gold Nanoclusters. J. Am. Chem. Soc. 2012, 134, 13316-13322. DOI: 10.1021/ ja3032339. 
(26) Malola, S.; Henkelman, G. Chiral Inversion of Thiolate-Protected Gold Nanoclusters via Core Reconstruction without Breaking a Au-S Bond. J. Am. Chem. Soc. 2019, 141, 6006-6012. DOI: $10.1021 /$ jacs.9b01204.

(27) Van Lehn, R. C.; Atukorale, P. U.; Carney, R. P.; Yang, Y. S.; Stellacci, F.; Irvine, D. J.; Alexander-Katz, A. Effect of Particle Diameter and Surface Composition on the Spontaneous Fusion of Monolayer-protected Gold Nanoparticles with Lipid Bilayers. Nano Lett. 2013, 13, 4060-4067. DOI: 10.1021/n1401365n.

(28) Hainfeld, J. F.; Slatkin, D. N.; Smilowitz, H. M. The Use of Gold Nanoparticles to Enhance Radiotherapy in Mice. Phys. Med. Biol. 2004, 49, N309-N315, DOI: 10.1088/00319155/49/18/n03.

(29) Zhang, X.-D.; Chen, J.; Luo, Z.; Wu, D.; Shen, X.; Song, S.-S.; Sun, Y.-M.; Liu, P.-X.; Zhao, J.; Huo, S.; Fan, S.; Fan, F.; Liang X.-J.; Xie, J. Enhanced Tumor Accumulation of Sub-2 nm Gold Nanoclusters for Cancer Radiation Therapy. Adv. Healthcare Mater. 2014, 3, 133-141, DOI: 10.1002/adhm.201300189.

(30) Zhang, X.-D.; Luo, Z.; Chen, J.; Shen, X.; Song, S.; Sun, Y.; Fan, S.; Fan, F.; Leong, D. T.; Xie, J. Ultrasmall Au(10-12)(SG)(10-12) Nanomolecules for High Tumor Specificity and Cancer Radiotherapy. Adv. Mater. 2014, 26, 4565-4568, DOI: 10.1002/adma.201400866.

(31) Chan, C. H.; Poignant, F.; Beuve, M.; Dumont, E.; Loffreda, D. A Water Solvation Shell Can Transform Gold Metastable Nanoparticles in the Fluxional Regime. J. Phys. Chem. Lett. 2019, 10, 1092-1098. DOI: 10.1021/acs.jpclett.8b03822. 
(32) Santiago-Rodriguez, Y.; Herron, J. A.; Curet-Arana, M. C.; Mavrikakis, M. Atomic and Molecular Adsorption on Au(111). Surf. Sci. 2014, 627, 57-69. DOI: 10.1016/j.susc.2014.04.012.

(33) Ting, E. C.; Popa, T.; Paci, I. Surface-site Reactivity in Small-molecule Adsorption: A Theoretical Study of Thiol Binding on Multi-coordinated Gold Clusters. Beilstein J. Nanotechnol 2016, 7, 53-61. DOI: 10.3762/bjnano.7.6.

(34) Guesmi, H.; Luque, N. B.; Santos, E.; Tielens, F. Does the S- H Bond Always Break after Adsorption of an Alkylthiol on Au (111)? Chem. Eur. J. 2017, 23, 1402-1408. DOI: 10.1002/chem.201604574.

(35) Umeyama, H.; Morokuma, K. The Origin of Hydrogen Bonding. An Energy Decomposition Study. J. Am. Chem. Soc. 1977, 99, 1316-1332. DOI: 10.1021/ja00447a007.

(36) Benoit, D. N.; Zhu, H.; Lilierose, M. H.; Verm, R. A.; Ali, N.; Morrison, A. N.; Fortner, J.D.; Avendano, C.; Colvin, V. L. Measuring the Grafting Density of Nanoparticles in Solution by Analytical Ultracentrifugation and Total Organic Carbon Analysis. Anal. Chem. 2012, 84, 92389245. DOI: 10.1021/ac301980a.

(37) Lu, J.; Xue, Y.; Shi, R.; Kang, J.; Zhao, C. Y.; Zhang, N. N.; Wang, C. Y.; Lu, Z. Y.; Liu, K. A Non-sacrificial Method for the Quantification of Poly (Ethylene Glycol) Grafting Density on Gold Nanoparticles for Applications in Nanomedicine. Chem. Sci. 2019, 10, 2067-2074. DOI: 10.1039/C8SC02847H.

(38) Rahme, K.; Chen, L.; Hobbs, R. G.; Morris, M. A.; O'Driscoll, C.; Holmes, J. D. PEGylated Gold Nanoparticles: Polymer Quantification as a Function of PEG Lengths and Nanoparticle Dimensions. $R S C A d v$. 2013, 3, 6085-6094. DOI: 10.1039/C3RA22739A. 
$\mathrm{Au}_{54}$ (deca) $\quad \mathrm{Au}_{55}$ (ico)

$\mathrm{Au}_{55}$ (ino)

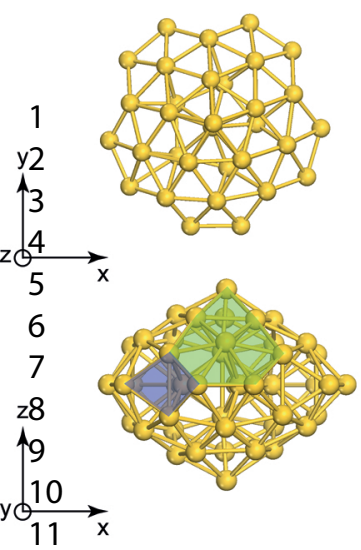
The Journal of Physical Chemistry Letters
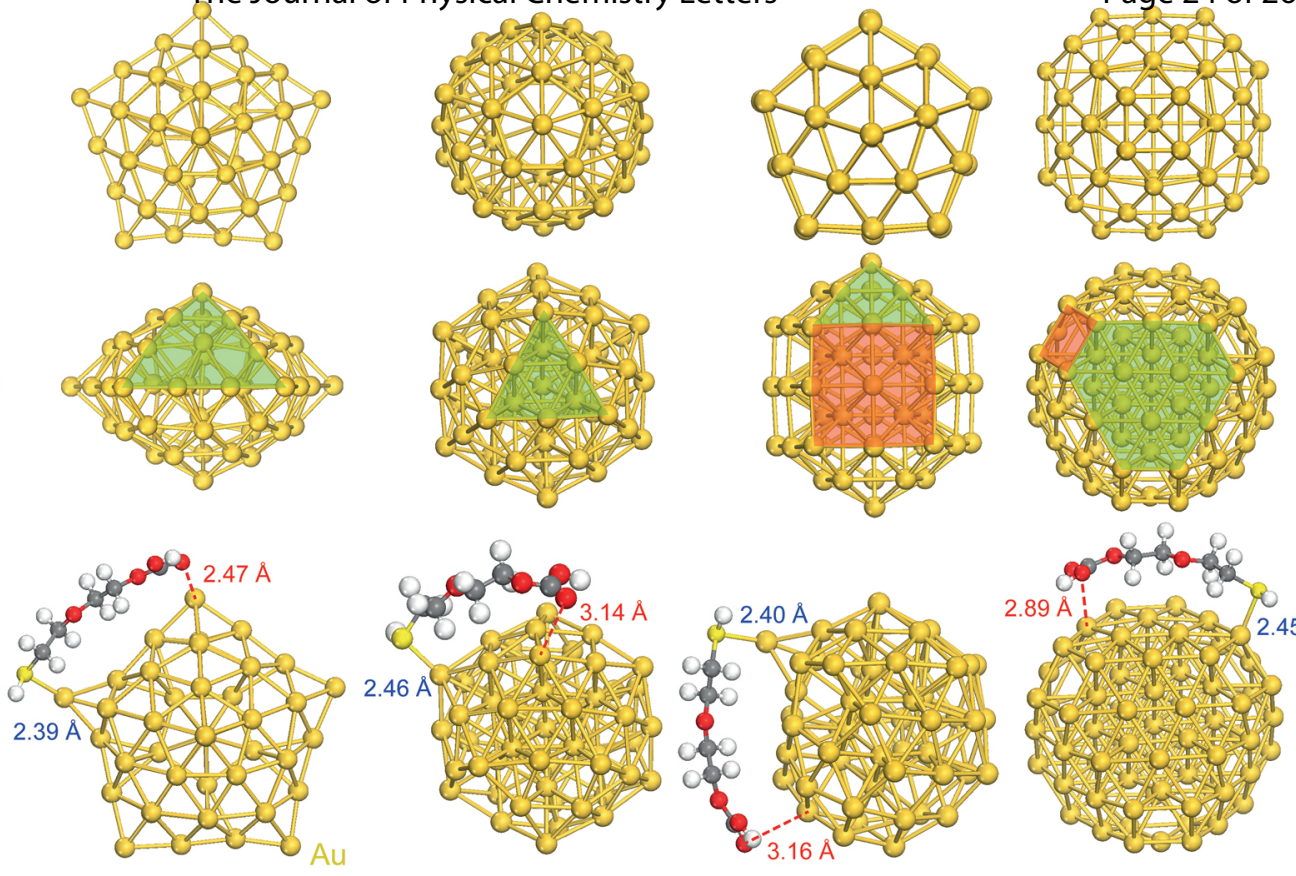

19

20

21

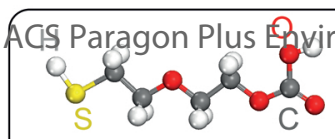

PEG molecule

$\mathrm{Au}_{79}$ (ito)

Page 24 of 26

Pिल
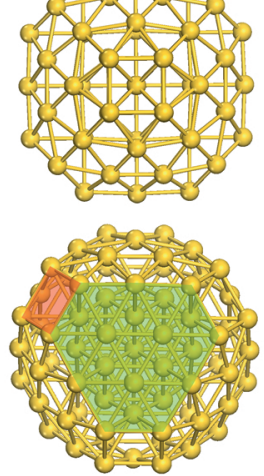

22

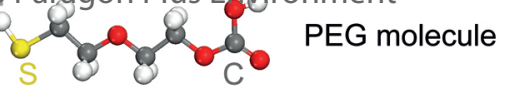


(c)

Thers P PErGal of Physical Chemistry Letters

$$
\begin{aligned}
& \mathrm{N}_{\mathrm{c}}=17 ; \mathrm{N}_{\mathrm{p}}=9 \\
& \theta_{\text {chem }}=0.41 \mathrm{ML}
\end{aligned}
$$

$1.40 \%$

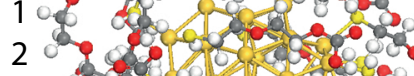

(b) 10

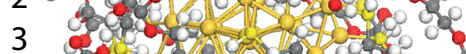
4004020

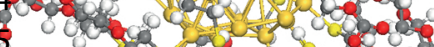
60.006000

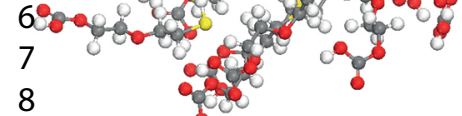
9

12

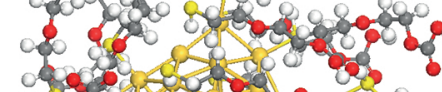
15 o con 8 . 170 ofore $18 \%$ g 2012 19 20 21

22

23

24

25

26

27

29 30 31

32

33

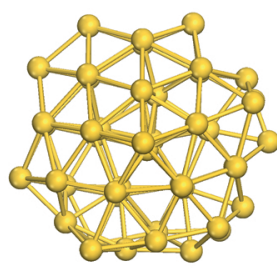

$\mathrm{Au}_{54}$ (deca) 26 PEG

$\mathrm{N}_{\mathrm{c}}=19 ; \mathrm{N}_{\mathrm{p}}=7$ $\theta_{\text {chem }}=0.40 \mathrm{ML}$

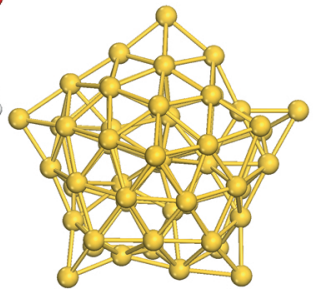
1 gas 1808 \& 11 22

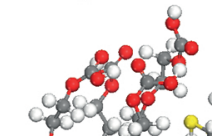
808960 98008000 34

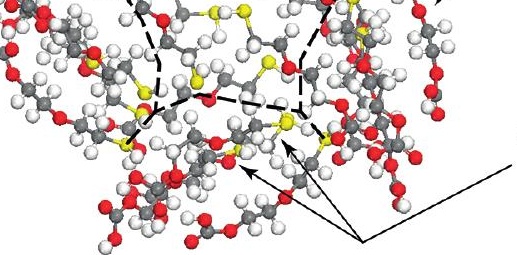

PEG

(d)

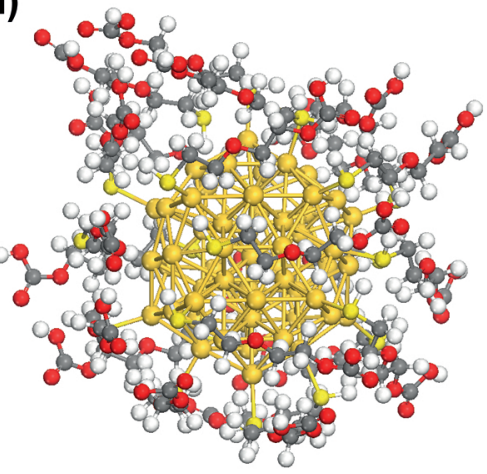

(e)

physiserbegon Plus Enviroonien oto PEG

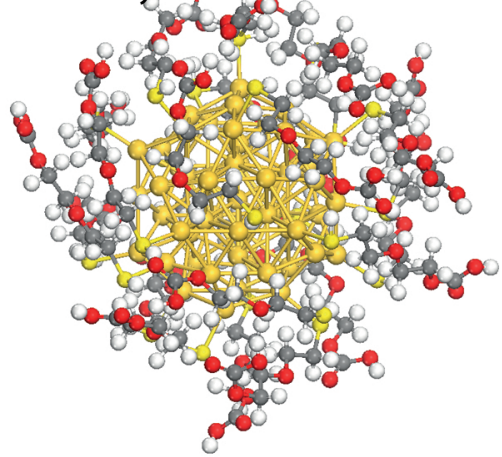

$\mathrm{Au}_{55}$ (ico)

2 PEG

$\mathrm{N}_{\mathrm{c}}=19 ; \mathrm{N}_{\mathrm{p}}=3$

$\theta_{\text {chem }}=0.45 \mathrm{ML}$

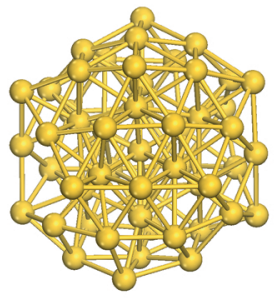

$\mathrm{Au}_{55}$ (ino)

22 PEG

$\mathrm{N}_{\mathrm{c}}=18 ; \mathrm{N}_{\mathrm{p}}=4$

$\theta_{\text {chem }}=0.43 \mathrm{ML}$

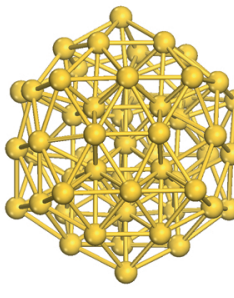

$\mathrm{Au}_{79}$ (ito)

32 PEG

$N_{c}=27 ; N_{p}=5$

$\theta_{\text {chem }}=0.45 \mathrm{ML}$

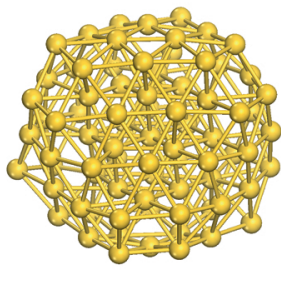




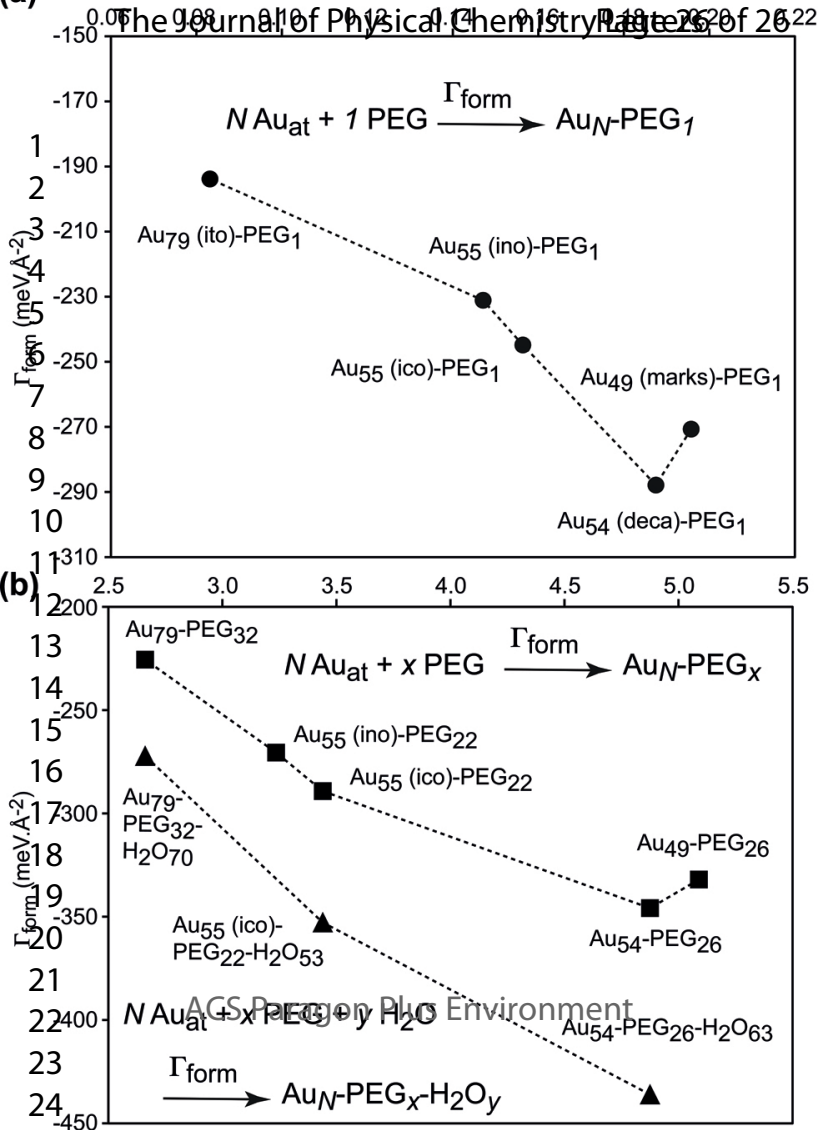

(a)

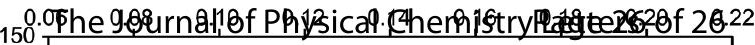

$N A u_{\text {at }}+1$ PEG $\stackrel{\Gamma_{\text {form }}}{\longrightarrow} A_{N}-P E_{1}$

$\mathrm{Au}_{55}$ (ico)-PEG 1

$\mathrm{Au}_{54}$ (deca)-PEG 1

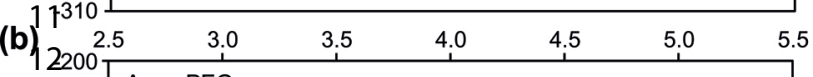

$\mathrm{Au}_{79}-\mathrm{PEG}_{32} \quad \Gamma_{\text {form }}$

$\mathrm{Au}_{N}-\mathrm{PEG}_{X}$

$\mathrm{Au}_{55}$ (ico)-

$\mathrm{Au}_{54}-\mathrm{PEG}_{26}$

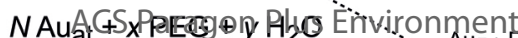

